\title{
Research Paper: Psychological Impact of the Acute COVID-19 Period on Patients With Substance Use Disorders: We are all in this Together
}

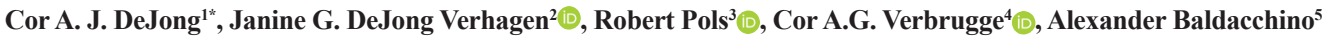 \\ 1. Behavioral Science Institute, Radboud Universiteit Nijmegen, The Netherlands. \\ 2. Integral Recovery [Integraal Herstel], Wychen, The Netherlands. \\ 3. Mental Health Organization (MHO) GGZ Oost Brabant, The Netherlands. \\ 4. Novadic-Kentron Addiction Care, Vught, The Netherlands. \\ 5. Division of Population and Health Sciences, University of St Andrews, St Andrews, Fife, Scotland, UK.
}

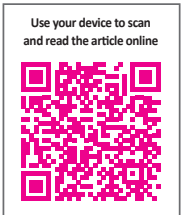

Citation: DeJong, C. A. J., DeJong Verhagen, J. G., Pols, R., Verbrugge, C. A.G., \& Baldacchino, A. (2020). Psychological Impact of the Acute COVID-19 Period on Patients With Substance Use Disorders: We are all in this Together. Basic and Clinical Neuroscience, 11(2.Covid19), 207-216. http://dx.doi.org/10.32598/bcn.11.covid19.2543.1

http://dx.doi.org/10.32598/bcn.11.covid19.2543.1

Article info:

Received: 15 Apr 2020

First Revision: 16 Apr 2020

Accepted: 22 Apr 2020

Available Online: 28 Apr 2020

Keywords:

Acute coronavirus epidemic, COVID-19, Therapeutic alliance, Professional patient relations, Psychological stress, Trauma and stressor-related disorders, Shared traumatic stress, Shared decision making $\underline{\text { A B S T RAC T }}$

Introduction: Coronavirus Disease 2019 (COVID-19) results from Severe Acute Respiratory Syndrome Coronavirus 2 (SARS-CoV-2). it is now a pandemic that affects us all. For patients referring to the addiction care systems, this pandemic can create additional vulnerabilities. A great deal of effort has made to re-organize the care systems for patients with addiction. Our study focuses on the voice of our patients, on clues to adapt treatment, and on the impact of the pandemic on the therapeutic alliance.

Methods: A qualitative design was used to develop a description and understanding of general and clinically relevant aspects of the impact of the COVID-19 pandemic. Fifteen addicted patients (11 under treatment and 4 in recovery) were interviewed by 4 interviewers according to the COREQ (consolidated criteria for reporting qualitative research).

Results: COVID-19 has had a serious impact on thoughts, feelings, and behaviors. Interviewees shared their anxieties about their health and the health of their relatives. Frightening thoughts were associated with a range of negative feelings and behaviors, such as stress, anger, avoidance, and isolation. The use of psychoactive substances differed between the patients in treatment with those who are in stable recovery. In the former, all succeeded in staying abstinent. They have experienced that solidarity and connectedness were essential in sustaining their recovery. Those still in treatment were fighting against the temptation to start using again; they felt emotionally isolated and sometimes patronized by health care workers.

Conclusion: The elaboration of the interviewees on the therapeutic relationship provides promising clues to optimize that relationship. Remembering this common expression, "we are all in this together", shared decision making could very well be used to shape effective and receptive treatment interventions during the different challenges faced at different stages of the COVID-19 epidemic.

\footnotetext{
* Corresponding Author:

Cor A. J. DeJong, PhD.

Address: Behavioral Science Institute, Radboud Universiteit Nijmegen, The Netherlands.

Tel: +31 (0) 651270926

E-mail: nispa.dejong@gmail.com
} 


\section{Highlights}

- COVID-19 influenced the lives of addicted patients in a way that is comparable with how we are all affected all by the pandemic.

-Because of the mostly negative thoughts, feelings and behavior the interviewees in treatment were vulnerable to relapse.

- Thoughts, feelings and behavior forms a good basis for a behavioral therapeutic intervention by making a functional analysis and challenging irrational thoughts and looking together for more rational thoughts that can reduce negative feelings.

- Therapy has changed by necessary rules to mitigate COVID-19 spread, and patient and health care worker both are troubled by it. Just as Shared Decision Making helps to start a treatment, improves the working alliance, the adherence and the efficacy, this method could very well be used to shape effective and receptive treatment interventions during the different challenges faced at different stages of the COVID-19 epidemic.

\section{Plain Language Summary}

On several occasions it was suggested that it would be good to make addicted patients' voices heard in this COVID-19 pandemic. Anecdotes are not suitable for this, so we conducted in the second week of April a qualitative study. We were able to develop a description and understanding of general and clinically relevant aspects of the impact of pandemic. Interviewees shared anxieties about their health and the health of their relatives. Frightening thoughts were associated with a range of negative feelings and behaviors such as stress, anger, avoidance and isolation. The use of psychoactive substances differed between the patients in treatment with those who are in stable recovery. In the former all succeeded in staying abstinent. They have experienced that solidarity and connectedness were essential in sustaining their recovery. Those still in treatment were fighting against the temptation to start using again, they felt emotionally isolated and sometimes patronized by health care workers. The elaboration of the interviewees on the therapeutic relationship provides promising clues to optimize that relationship. "We are all in it together!" Shared Decision Making could very well be used to shape effective and receptive treatment interventions during the different challenges faced at different stages of the COVID-19 epidemic.

\section{Introduction}

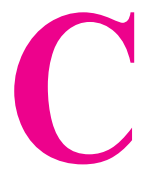

oronavirus Disease 2019 (COVID-19) results from Severe Acute Respiratory Syndrome Coronavirus 2 (SARS-CoV-2). It is now a pandemic that affects everybody with grave implications during the acute stage of the burden imposed on healthcare systems in all countries. Guidelines on how healthcare systems respond to the COVID-19 epidemic was initially formulated by the WHO (World Health Organization, 2020) and followed up by several national and regional contingency or continuity plans to divert non-essential services (especially around chronic non-communicable care delivery) to COVID19 intensive care units. This has also deployed a substantial amount of the workforce to unfamiliar environments. Besides, this workforce had to be trained, repurposed, and mobilized according to these rapidly designed essential services.
It is encouraging to note that a great deal of effort has also been put into the re-organization of the health care systems for patients with addiction disorders. In most countries, this service was deemed as an essential service that should be delivering before COVID19 care during this epidemic. To optimize health care services for our patients, researchers have issued numerous proposals (Farhoudian et al., 2020; Marsden et al., 2020) with detailed guidelines on contingencies to support continuity of service in both drug and alcohol users.

In general, as a reaction to an infectious disease outbreak like COVID19, there is a rapid increase in adverse psychological responses in the general population. They are reacting to this event with disbelief and confusion due to inadequate information, lack of insight, and poor communication by their authorities on how this will be resolved (Wang et al., 2020). According to this study, respondents rated the psychological impact of the out- 
break as moderate or severe. In particular, $16.5 \%$ of them reported moderate to severe depressive symptoms; $28.8 \%$ moderate to severe anxiety symptoms; and $8.1 \%$ moderate to severe stress levels. Most of them were worried about their family members contracting COVID-19 (75.2\%) (Wang et al., 2020).

Soon, tools have become available to deal with these psychological consequences during the acute phase but not during protracted episodes (Centers for Disease Control and Prevention, 2020). Additionally, there is an emerging number of (a) recovering and recovered $\mathrm{CO}$ VID19 individuals (Lee et al., 2007) and (b) healthcare intensivists and other health care workers (Tan et al., 2020) who are or will be experiencing Post-Traumatic Stress Disorder (PTSD) like symptoms as this period progresses even further from weeks to months and perhaps years. In the mean-time, there are rapidly emerging help centers to support individuals with mental healthrelated problems (Center for Addiction and Mental Health, 2020) but again they have been erected for the acute phase of this global epidemic (Center for Addiction and Mental Health, 2020).

For the patients who use mental health and addiction care systems, this pandemic can create additional vulnerabilities on their physical and psychological health (Volkow, 2020). Additionally, chronic, potentially lifethreatening, and stressful events increase the risk of relapse (McCabe, Cranford, \& Boyd, 2016).

While mental health care workers will not be on the frontline confronting and treating acute COVID-19 disease, they may experience the same emotional responses as everyone else in the general population and perhaps even more. If that is the case, one can imagine the possibility that a vulnerable patient would be meeting an anxious, depressed, or stressed mental health care worker during this pandemic. It is pertinent therefore to take on the learning points from experience on the therapeutic relationships during the prolonged crisis from other traumatic events such as conflicts and natural disasters (Baum, 2010), as treatment could be compromised because of the personal and professional impact of these traumatic events on health care workers (Tosone, McTighe, \& Bauwens, 2015). Guidelines for dealing with these situations were initiated and considered as helpful (American Psychological Association, 2001) in the future.

Although it is too early to study the full psychological impact of the COVID-19 global epidemic on dyads of patients and health care workers within the mental health and addiction treatment systems, it is important to start asking patients about how they perceive the therapeutic relationship impacted on their lives for now.

Listening to the voice of the patients who use our mental health and addiction care systems is important not only to understand better their concerns but it also provides unique and helpful insight on one of the cornerstones of treatment, namely the therapeutic working alliance (Cook, Heather, \& McCambridge, 2015). The purpose of this small qualitative person-centered study was to explore further the above issues.

Our exploration has three aims. Firstly, we want to listen to the voice of our patients. In other words, what they say about how the pandemic affects them. The second aim was to find clues in the answers of the patients that could be used to adapt a treatment that uses the principles of Cognitive Behavioral Therapy (CBT) to support a therapeutic intervention that allays the fears and anxieties expressed by the patients during this global pandemic. Finally the last aim was to explore the impact of this pandemic on their therapeutic relationship with their health care workers.

\section{Methods}

\subsection{Study design}

We conducted a qualitative exploration following a phenomenological approach to develop a description and understanding of general and clinically relevant aspects of the impact of the COVID-19 pandemic in addicted patients. We used the Consolidated Criteria For Reporting Qualitative Research (COREQ) to ensure the quality of the process, including aspects of the team, study methods, findings, analysis and interpretations (Tong, Sainsbury, \& Craig, 2007) (The COREQ checklist of this study is attached as supplementary material). We wanted to interview respondents as much as is needed to achieve saturation. There is no rule of thumb for the number of respondents to be included in a naturalistic exploration as we planned to perform. Therefore we used a constant comparative method (Bowen, 2008), meaning that it was checked by the first author with every new interview if new themes emerge.

\subsection{Study setting}

The study population consisted of patients with Substance Use Disorder (SUD) under treatment $(n=11)$ and in recovery $(n=4)$ in the southeastern part of the Netherlands. This region was affected early during the pandemic, in March 2020, and up to now (May 4, 2020) 
it has experienced the highest prevalence of COVID19 infected people (8404 out of a total of $40571 ; 2.0,7 \%$ ), hospitalized (2596 out of a total of $10995 ; 23.6 \%$ ) and deaths (1392 out of a total of 5056; 27.5\%).

\subsection{Selection of participants}

We included 11 participants from our clinical practice (CDJ, JGDJV, and RP; n=9) or non-clinical projects $(\mathrm{CV} ; \mathrm{n}=2)$. RP and $\mathrm{CV}$ knew the four interviewees in stable recovery from their circle of acquaintances. None of us was the patients' health care professional directly responsible for their treatment plans.

\subsection{Study Procedure}

Before the interview, we asked the participants to answer a few questions regarding their demographics and clinical features such as gender, age, psychiatric and addiction history, and treatment setting. Regarding COVID-19, we asked them if they had presented with COVID-19 symptoms, if anyone in their immediate area had been sick, and if someone had died from the infection. We developed a semi-structured interview with five relevant sets of open questions relating to key topics of impact (Thoughts, feelings, and behavior) of the COVID-19 pandemic (Table 1). The first two sets of questions were related to the general experiences of the interviewee and his or her environment. The third and fourth addressed the impact on their use of psychoactive substances and their environment. The final question concerns the influence of COVID-19 on their treatment and their relationship with the health care worker.

Each set of questions consisted of three parts based on the core of CBT: thoughts, feelings, and behavior.

\subsection{Data collection}

The patients were informed about the background and aims of the interview. We believed that conducting the interviews quickly and submitting a good scientific article was important, but taking the ethical approval would delay this procedure. Therefore, we have formulated the following requirements for participation. In case of refusal to be interviewed, there were no negative consequences for the patients. They were informed that they had the right to leave the interview without any negative further consequences. There were no incentives for participation in the interview. The interview itself was lim-

Table 1. Core questions of the semi-structured interview Introduction: The following questions are about the impact of the Corona epidemic. We contact you because you are being treated for the use of alcohol or drugs.

\begin{tabular}{|c|c|}
\hline Core Questions & Secondary Questions \\
\hline $\begin{array}{l}\text { 1. The Corona } \\
\text { epidemic affects } \\
\text { everyone. We would } \\
\text { like to know how it } \\
\text { affects you. }\end{array}$ & $\begin{array}{l}\text { A. When you think about Corona, what do you think about this? } \\
\text { B. If you consider Corona, what does the epidemic do to your feelings? } \\
\text { C. If you consider Corona, how does it affect your behavior/actions? }\end{array}$ \\
\hline $\begin{array}{l}\text { 2. What does the Co- } \\
\text { rona epidemic do to } \\
\text { your environment? }\end{array}$ & $\begin{array}{l}\text { A. How do people around you, your family, friends, or partner speak about the Corona epidemic? } \\
\text { B. How do you feel about the feelings of people around you, your family, friends or partner when it comes to } \\
\text { the Corona epidemic? } \\
\text { C. Do they behave differently during this time of the Corona epidemic? If so, what do you notice? }\end{array}$ \\
\hline $\begin{array}{l}\text { 3. The following ques- } \\
\text { tions are about what } \\
\text { the Corona epidemic } \\
\text { means to you in } \\
\text { terms of your use of } \\
\text { substances? }\end{array}$ & $\begin{array}{l}\text { A. How do you think the Corona epidemic will affect your use of substances? What do you think about this? } \\
\text { B. If you think there is a relationship between Corona and your use of substances, what feelings does that } \\
\text { evoke in you? } \\
\text { C. If you think there is a relationship between Corona and your use of substances, how will this affect your } \\
\text { behavior? }\end{array}$ \\
\hline $\begin{array}{l}\text { 4. What does the } \\
\text { Corona epidemic do } \\
\text { to your environment } \\
\text { when it comes to } \\
\text { your use of sub- } \\
\text { stances? }\end{array}$ & $\begin{array}{l}\text { A. How do people around you, your family, friends, or partner speak about the Corona epidemic and your use } \\
\text { of substances? } \\
\text { B. What do you think people in your environment feel when it comes to the Corona epidemic and your use of } \\
\text { substances? } \\
\text { C. How do people around you, your family, friends, or partner behave towards you and your use of substances } \\
\text { in this Corona epidemic? }\end{array}$ \\
\hline $\begin{array}{l}\text { 5. What does the } \\
\text { Corona epidemic do } \\
\text { with your treat- } \\
\text { ment of your use } \\
\text { of substances? Is it } \\
\text { different? }\end{array}$ & $\begin{array}{l}\text { A. Do you think that Corona has or will have an influence on your treatment? } \\
\text { B. How does it feel to be treated during the Corona epidemic? } \\
\text { C. Do you notice that the Corona epidemic affects your behavior during your treatment? } \\
\text { D. How do health care workers speak about the Corona epidemic and your use of substances? } \\
\text { E. What do you think health care workers feel when it comes to the Corona epidemic and your use of sub- } \\
\text { stances? } \\
\text { F. How do health care workers behave towards you and your use of substances in this Corona epidemic? }\end{array}$ \\
\hline
\end{tabular}


Table 2. Characteristics of the study sample

\begin{tabular}{|c|c|}
\hline Variables & Description \\
\hline Mean age in years (SD; range) & $39.2(8.1 ; 27-51)$ \\
\hline Gender (male/female) & $11 / 4$ \\
\hline Psychiatric diagnosis $(n)^{*}$ & $\begin{array}{l}\text { Anxiety disorder (3), Affective disorder (3), ADHD (3), } \\
\text { PTSD (2), Schizophrenia (2), Autism spectrum disorder (1), Bulimia nervosa (1) }\end{array}$ \\
\hline Substance use disorder and gambling $(n)^{*}$ & $\begin{array}{c}\text { Alcohol (8), Cannabis (7), Cocaine (3), Opioid (2), Stimulant (1), Anxiolytic (1), } \\
\text { Ketamine (1), Gambling (1) }\end{array}$ \\
\hline Setting $(n)$ & $\begin{array}{c}\text { Outpatient (8) } \\
\text { Inpatient (3) } \\
\text { Stabile Recovery (4) }\end{array}$ \\
\hline COVID-19 (Yes/No) & $\begin{array}{c}\text { Self: } 2 / 13 \\
\text { Close relatives: } 8 / 7 \\
\text { Death of close relatives: } 2 / 13\end{array}$ \\
\hline
\end{tabular}

${ }^{*}$ Multiple diagnoses per patient

NEUR:SCIENCE

ited to 25 minutes. All interviews were conducted over the phone. The interviewers had a copy of the interview (Table 1) at hand and wrote the answers as much they could in a column next to the questions.

\subsection{Thematic analysis:}

The written interviews were recorded in a Word document and with each new interview the themes emerging from the answers were compared with the earlier ones. At the 14th and 15th interviews no new themes emerged. The next step was to rearrange all the results according to the five core questions and then with reference to thoughts, feelings, and behavior.

Next, the resulting document was independently analyzed by three authors (CDJ, JGDJV, and CV) on main themes within the categories of thoughts, feelings, and behavior of each of the 5 question sets. Their results were discussed in a virtual meeting and disagreements on the grouping of themes and subtopics were resolved through consensus.

\section{Results}

\subsection{Characteristics of the sample}

A consecutive series of 15 individuals were asked to participate in our research. All accepted to cooperate and gave their oral consent. Their sociodemographic characteristics are presented in Table 2. The participants were between 27 and 51 years old (mean age $=39$ years). Most interviewees reported a psychiatric diagnosis in combination with a substance-related disorder. Saturation started after the 13th interview. Nine of them were directly affected by COVID-19. Two were sick themselves, 8 had a close relative affected by the disease, and
2 of them lost a close relative due to COVID-19 related illness.

3.2. Overview of the perception of the impact of COVID-19

All interviewees reported an impact on them by the COVID-19 epidemic. Overall these experiences could be divided separately on their thinking, feeling, and behavior, but of course they are all narrowly associated. The prevalence of negative experiences was far more prevalent than neutral or positive experiences. They appreciated being able to share their concerns, albeit in a phone call.

\subsection{Effects on the interviewees}

Most thoughts about the psychological impact were expressed as concerns about one's health and that of others: "I think I can get sick just like that, others died". This period of COVID-19 pandemic was perceived as dangerous, especially for vulnerable persons such as parents with, for example, a chronic condition. It also created confusion: "When I was addicted I isolated myself, now I am abstinent and I have to isolate myself!". Some experienced temporary relief: "I think that's a pleasant thought that the bars are closed". or "All festivals have been canceled and that gives me peace of mind". A few who lived in isolation before the COVID-19 epidemic reported no positive or negative thoughts.

The reported feelings were almost all negative, ranging from angriness, guilt, gloom, fear, panic, restlessness, stress, annoying, unsafety, fright, or stress: "Father was ill and in the hospital, I was not allowed to go there. That was very difficult for me". An interviewee said he felt 
'fairly calm', a young interviewee said, 'I'm not afraid, I'm young and energetic".

The outcome with regard to behavior can be summarized as keeping social distance and includes closing yourself off to others, withdrawing, staying at home, and avoiding contact. Despite the isolation, not everyone could find a quiet or relaxing moment, especially if one lived in a house with several occupants: "With four adolescents at home, it is not easy to find some peace for me". Almost everyone adheres to the hygienic advice and the $1.5 \mathrm{~m}$ distance rule and finally accepts that it is what it is: "I follow the guidelines, I am more alert and tense and finally realize that I have no control and then surrender to the situation".

\subsection{Perceived effect on the environment}

According to the experience of the interviewees, close relatives react differently, ranging from worried, accepting to casual. There seems to be a difference in reactions between younger and older relatives: "Young people are laconic, see less danger. The elderly are more anxious, more cautious, worrying". The abstinent patients and those in stable recovery mentioned that people in their environment seemed to be afraid that they will relapse because of the stress raised by COVID-19. Furthermore, they noticed more stress, irritation, and anxiety than usual. Some were happy that their family members expressed hope and confidence. The interviewees noted that people in their environment were isolating or hoarding due to the crisis. In general, the lack of physical contact was missed by everyone: "There are hardly any visitors, and if there is someone I miss a hug".

\subsection{Effects on the use of alcohol and drugs by the interviewees}

There were certainly negative effects of the epidemic on the use of alcohol and drugs. It was more difficult to get health care, and especially to get their methadone prescription. Barriers to abstain were lower: "As said before, sitting at home leads to boredom and makes it easier to grab a beer, you say 'yes' to yourself more easily". Some reported no effect on their drug or alcohol use: "I have been clean for 1.5 years now. I am strong enough not to fall back. Learned a lot in the past year". Depending on the stage of recovery, feelings were different. Patients who were recently detoxified were concerned about relapsing, experienced more stress and craving, and felt powerless. Those in stable recovery saw no effect and realized that the use of alcohol or drugs will not help to cope with the negative state caused by the CO-
VID-19 epidemic: "Then I would feel like a weakling because I grab every situation to start using again". In relapsing patients, the craving was that strong that they went to the shop to buy alcohol or heroin by the dealer without thinking of the consequences: "Getting alcohol every day is more important for me than the fear of being contaminated in the store". Some of the interviewees managed to stay abstinent by going for a walk or go shopping: "Although a daily visit to a supermarket is not recommended, I still do it, precisely not to let my social isolation increase even more". For most, keeping structure was an important means of preventing a relapse.

3.6. Perceived effect on the environment with regard to the use of alcohol and drugs by the interviewees

Close relatives were usually constructively concerned: "They mainly ask if I can keep it up, knowing that I am isolated". Some, however, experienced a more negative attitude in their environment: "I always feel that I am 'waste' because I am addicted and my children are in youth care and now it is even worse". Other interviewees lived close to other people who used drugs and in front of them. They were relaxed and unconcerned and behaved laughably: "I am now more often confronted with roommates who smoke cannabis; that doesn't make it easier to remain clean!"

\subsection{Effect on the treatment of the interviewees}

The greatest common denominator in all the interviews conducted was the change in the way treatment was provided. Much attention was paid to the changed rules. There were almost no face-to-face contacts anymore. Communication to the healthcare provider was conducted via telephone and or a video reducing connectedness: "I think the core problem in tackling addiction is being able to reconnect with your environment. Now that is hindered by Corona". Access to health care was more difficult. Sometimes therapy appointments were delayed or canceled. For one interviewee, this was a positive experience: "It works positively for me, it is calmer, less intensive, I have more time to think about feelings". Day activities were canceled, leading to a less structured daily life for others. Inpatient treatment was more disorganized; suddenly there were other health workers deployed from other settings and or transfers of other patients from wards vacated to create COVID-19 red zoned units. Significantly during therapy sessions, the interviewees were asked little or nothing about what the COVID-19 epidemic meant to them. 
The changes in treatment raised negative feelings. Online interventions were not well appreciated: "They also make me feel more stressed". Cancellation of treatment can result in feelings of anger, rejection, and despair: "If you have just abstained from alcohol or drugs and you are all alone at home, it is very difficult, especially if you no longer have contact with a health care worker".

\subsection{Perceived effect on the health care workers}

Health care workers regularly speak about the rules with their patients that have changed by the COVID-19 epidemic. They were very concerned about what these rules exactly meant but they also seemed to experience much confusion about their interpretation of these rules: "They are agitated and therefore seem to be more concerned with themselves and no longer with the department". Five interviewees explicitly mentioned that their health care workers did not speak anything about the COVID-19 epidemic with them.

For most of the interviewees, it was clear that their health care workers were also concerned and that they expressed feelings of insecurity, powerlessness, and stress in a dysfunctional manner with clear implications to the therapeutic relationships.

Lack of appropriate technology that is supported by face to face interactions did not help with the above thoughts and feelings: "Sometimes the telephone connection drops and I don't get a call back either". On one occasion, the reaction by the system was draconian: "These are the rules, so there is nothing we can do for you". Patients in stable recovery were fully aware of their values and renewed skills of self-empowerment and self-sufficiency. However, they also missed the calls from their former health care worker asking them about the impact and how they are dealing with minimizing the risk of relapse.

\section{Discussion}

After listening to the voice of our patients, it became clear that the COVID-19 global epidemic has had a serious impact on the thoughts, feelings, and behavior of the interviewees attending mental health and addiction care systems. They shared anxieties about their health and the health of their relatives. They had frightening thoughts associated with a wide range of negative feelings and behavior, such as stress, anger, avoidance, and isolation. The psychological responses as expressed in thoughts, feelings, and behavior are understandable responses to an impending crisis and are not much dif- ferent from those mentioned by the general population (Fardin, 2020; Wang, et al., 2020), the patients infected with COVID-19 (Lee et al., 2007) or health care workers taking care of COVID-19 patients (Tan et al., 2020).

The second goal was to find clues in the patients' answers that could be used to tailor a treatment that uses the principles of CBT to the concerns that everyone can have during this global pandemic. In this respect, it is acknowledged that negative thoughts and fears are natural at this time. At the same time, taking a balanced perspective, not assuming the worst, and taking the longterm optimistic view can help reduce anxiety and stress (World Confederation Of Cognitive And Behavioral Therapies, 2020). When a patient expresses such concerns, the health care worker can use general principles of CBT: challenging unhelpful thoughts and encouraging the patient to take a balanced perspective, easing physical stress and tension (e.g. relaxation exercises or meditation and mindfulness), and engaging in helpful behavior (e.g. engage in pleasant events or problemsolving).

The specific effect of the COVID-19 epidemic on the use of psychoactive substances was different in the patients in treatment compared with those who are in stable recovery. In the former case, some succeeded in staying abstinent, but most were fighting against the craving and the temptation to start using again with some relapsing. Causality, of course, could not be demonstrated, but it is well known that life events such as COVID-19 epidemic can lead to relapse (Jessup et al., 2014; McCabe, et al., 2016; Pilowsky, Keyes, Geier, Grant, \& Hasin, 2013). Our four patients in a stable recovery managed to stay abstinent. They used CBT rules such as asking for help, not bending the rules, and practicing self-care (Melemis, 2015). The patients in recovery most clearly indicated that they had learned not to isolate themselves when everything gets tough. They have experienced that solidarity and connectedness were essential in sustaining their recovery. The interviewees who were still under treatment also noticed that distance has not only become physical but that they also felt emotionally isolated and sometimes patronized.

Additionally, the COVID-19 pandemic has affected relatives which increased the interviewees' concerns about the effect on their family member's recovery journey. Family members are an important resource to support recovery (Andersson et al., 2018). It was encouraging that interviewees experienced that close relatives were usually constructively concerned. Perceptions of reactions of non-relatives in the environment were less 
positive and referred perhaps to earlier perceptions of stigmatization (Yang, Wong, Grivel, \& Hasin, 2017) in society and or a flare-up of self-stigmatizing thoughts in times of crisis (Corrigan \& Rao, 2012; Matthews, Dwyer, \& Snoek, 2017).

All interviewees reported mostly negative effects of the COVID-19 epidemic on their treatment with special emphasis on the sudden changes in the rules of engagement during their treatment and the subsequent difficulties arising as practitioners are trying to deal with these changes. International policy institutions such as the World Health Organisation (WHO) and international professional organizations such as the International Society of Addiction Medicine (ISAM) have stated in the early phase of this crisis that health care institutions must adapt and provide the roadmap to reorganize such systems (Farhoudian et al., 2020; World Health Organization, 2020). Our interviewees endorsed this proactive approach. However, they also noted that their care providers are particularly busy adapting to those rules and are less focused on their patients.

It is clear from this small but patient-centered study that the participants have all experienced stress in one way or another as a result of this pandemic. If that is the case, we can more or less speak of a shared trauma which may negatively affect the working relationship and reduce the effectiveness of the treatment (Cook et al., 2015) offered. However, based on the perspective of shared trauma, we can also take this opportunity to look at how to approach treatment more constructively in this time of crisis than is currently the case.

In case of shared trauma, a health care worker should take care of oneself because personal vulnerability is not only a backdrop for clinical work but it also changes the frame of the work (Saakvitne, 2002). One may experience more or stronger feelings like fear, anxiety, sadness, or depression than what is expected. Normal responses like fatigue or absence from clinical practice can influence professional work and must be recognized and understood to be dealt with appropriately (American Psychological Association, 2001). Recognizing that a crisis can affect a patient, as well as the caregiver, highlights the importance of articulating the therapists' own trauma story and the urgent need to attend to the therapist's self-care before resuming clinical work. It also provides opportunities for enhanced therapeutic intimacy and caution regarding boundary alterations that may result from the therapist's self-disclosure (Tosone, NuttmanShwartz, \& Stephens, 2012).
We used a convenient sampling method to choose our study samples which will implicate strengths as well as limitations. First of all, this study is unique because it was conducted in situ during the acute phase of the epidemic when all the changes in health care identified by respondents occurred. All patients participated without hesitation and consented via e-mail or WhatsApp. The interviewees were under treatment (in- or out-patients) or in stable recovery. Many of them had experienced direct consequences of COVID-19 because they were infected by the virus or had a relative that was ill or even died. We realize that we have interviewed a small group so that the results cannot simply be generalized. Although we observed saturation after the 13 interviews, bias was to be expected because we did not interview homeless people and the interviews were conducted before the economic consequences of the COVID-19 epidemic.

Our exploration had thr ee aims. First, we listened to the voice of the patients and learned that COVID-19 influenced their lives in a way that is comparable with we all affected by the pandemic. The general impression is that because of the many negative thoughts, feelings, and behavior, the interviewees in treatment were more vulnerable to relapse. Besides the direct effect of the COVID-19 threat, another noticeable physical and emotional negative effect is social isolation.

The triad of thoughts, feelings, and behavior forms a firm basis for conducting the therapeutic conversation from a behavioral therapeutic framework. It starts by making a functional analysis and challenging irrational thoughts and looking together for more rational thoughts that can reduce negative feelings.

The elaboration of the interviewees on the treatment and especially on the relationship with their health care workers provides promising clues to optimize that relationship. "We are all in it together!" therapy has changed by necessary rules to mitigate COVID-19 spread, and patients and health care workers both are troubled by it. Just as shared decision making helps to start treatment (Joosten, De Weert-Van Oene, Sensky, Van Der Staak, \& De Jong, 2011), improves the working alliance (Joosten, de Weert, Sensky, van der Staak, \& de Jong, 2008), the adherence (Hell \& Nielsen, 2020; Joosten et al., 2008) and the efficacy (Joosten, de Jong, de Weert-van Oene, Sensky, \& van der Staak, 2009), this method could very well be used to shape effective and receptive treatment interventions during the different challenges faced at different stages of the COVID-19 epidemic. 


\section{Ethical Considerations}

\section{Compliance with ethical guidelines}

We believed that conducting the interviews quickly and submitting a good scientific article was important, but taking the ethical approval would delay this procedure. Therefore, we have formulated the following requirements for participation. The patients were informed about the background and aims of the interview. In case of refusal to be interviewed, there were no negative consequences for the patients. They were informed that they had the right to leave the interview without any negative further consequences. There were no incentives for participation in the interview. The interview itself was limited to 25 minutes. All interviews were conducted over the phone.

\section{Funding}

This research did not receive any specific grant from funding agencies in the public, commercial, or not-forprofit sectors.

\section{Authors' contributions}

Conceptualization, Methodology nad Original Draft: Cor A. J. DeJong; Investigation: Cor A. J. DeJong, Janine G. DeJong Verhagen, Robert Pols, Cor A.G. Verbrugge; Writing, Review \& Editing Cor A. J. DeJong, Janine G. DeJong Verhagen, Robert Pols, Cor A.G. Verbrugge, Alexander Baldacchino.

\section{Conflict of interest}

The authors declared no conflict of interest.

\section{Acknowledgments}

We thank the members of the ISAM (International Society of Addiction Medicine) PPIG COVID-19 survey group for their support.

\section{References}

American Psychological Association. (2001). Shared trauma: Helping clients cope with national events that affect the therapist. Retrieved from https://www.apaservices.org/practice/ce/ self-care/shared

Advisory Committee on Colleague Assistance. (2009). Shared trauma: Helping clients cope with national events that affect the therapist. Retrieved from https://www.apaservices.org/ practice/ce/self-care/shared

Andersson, C., Best, D., Irving, J., Edwards, M., Banks, J., MamaRudd, A., et al. (2018). Understanding recovery from a family perspective: A survey of life in recovery for families. Retrieved from http:// shura.shu.ac.uk/18890/

Baum, N. (2010). Shared traumatic reality in communal disasters: Toward a conceptualization. Psychotherapy (Chicago, Ill.), 47(2), 249-59. [DOI:10.1037/a0019784] [PMID]

Bowen, G. A. (2008). Naturalistic inquiry and the saturation concept: A research note. Qualitative Research, 8(1), 137-52. [DOI:10.1177/1468794107085301]

Centers for Disease Control and Prevention. (2020). Daily Life \& Coping. Retrieved from https://www.cdc.gov/ coronavirus/2019-ncov/daily-life-coping/managing-stressanxiety.html

Cook, S., Heather, N., McCambridge, J., \& United Kingdom Alcohol Treatment Trial Research Team. (2015). The role of the working alliance in treatment for alcohol problems. Psychology of Addictive Behaviors, 29(2), 371-81. [DOI:10.1037/ adb0000058] [PMID] [PMCID]

Corrigan, P. W., \& Rao, D. (2012). On the self-stigma of mental illness: Stages, disclosure, and strategies for change. Canadian Journal of Psychiatry, 57(8), 464-9. [DOI:10.1177/07067437120 5700804] [PMID] [PMCID]

Fardin, M. A. (2020). COVID-19 and anxiety: A review of psychological impacts of infectious disease outbreaks. Archives of Clinical Infectious Diseases, 15(COVID-19), e102779. [DOI:10.5812/archcid.102779]

Farhoudian, A., Baldacchino, A., Clark, N., Gerra, G., Ekhtiari, H., Dom, G., et al. (2020). COVID-19 and substance use disorders: Recommendations to a comprehensive healthcare response. An International Society of Addiction Medicine (ISAM) practice and policy interest group position paper. Basic and Clinical Neuroscience, 11(2), 129-46. [DOI:10.32598/ bcn.11.covid19.1]

Hell, M. E., \& Nielsen, A. S. (2020). Does patient involvement in treatment planning improve adherence, enrollment and other treatment outcome in alcohol addiction treatment? A systematic review. Addiction Research \& Theory. [DOI:10.1080/160 66359.2020.1723083]

Jessup, M. A., Ross, T. B., Jones, A. L., Satre, D. D., Weisner, C. M., Chi, F. W., et al. (2014). Significant life events and their impact on alcohol and drug use: A qualitative study. Journal of Psychoactive Drugs, 46(5), 450-9. [DOI:10.1080/02791072.2 014.962715] [PMID] [PMCID]

Joosten, E. A., de Jong, C. A., de Weert-van Oene, G. H., Sensky, T., \& van der Staak, C. P. (2009). Shared decision-making reduces drug use and psychiatric severity in substance-dependent patients. Psychotherapy and Psychosomatics, 78(4), 245-53. [DOI:10.1159/000219524] [PMID]

Joosten, E. A., De Weert-Van Oene, G. H., Sensky, T., Van Der Staak, C. P., \& De Jong, C. A. (2011). Treatment goals in addiction healthcare: the perspectives of patients and clinicians. The International Journal of Social Psychiatry, 57(3), 263-76. [DOI:10.1177/0020764009354835] [PMID]

Joosten, E. A., DeFuentes-Merillas, L., de Weert, G. H., Sensky, T., van der Staak, C. P., \& de Jong, C. A. (2008). Systematic re- 
view of the effects of shared decision-making on patient satisfaction, treatment adherence and health status. Psychotherapy and Psychosomatics, 77(4), 219-26. [DOI:10.1159/000126073] [PMID]

Joosten, E., de Weert, G., Sensky, T., van der Staak, C., \& de Jong, C. (2008). Effect of shared decision-making on therapeutic alliance in addiction health care. Patient Preference and Adherence, 2, 277-85. [DOI:10.2147/PPA.S4149] [PMID] [PMCID]

Lee, A. M., Wong, J. G., McAlonan, G. M., Cheung, V., Cheung, C., Sham, P. C., et al. (2007). Stress and psychological distress among SARS survivors 1 year after the outbreak. Canadian Journal of Psychiatry, 52(4), 233-40. [DOI:10.1177/070674370 705200405] [PMID]

Marsden, J., Darke, S., Hall, W., Hickman, M., Holmes, J., Humphreys, K., et al. (2020). Mitigating and learning from the impact of COVID-19 infection on addictive disorders. Addiction (Abingdon, England). [DOI:10.1111/add.15080] [PMID]

Matthews, S., Dwyer, R., \& Snoek, A. (2017). Stigma and selfstigma in addiction. Journal of Bioethical Inquiry, 14(2), 27586. [DOI:10.1007/s11673-017-9784-y] [PMID] [PMCID]

McCabe, S. E., Cranford, J. A., \& Boyd, C. J. (2016). Stressful events and other predictors of remission from drug dependence in the United States: Longitudinal results from a national survey. Journal of Substance Abuse Treatment, 71, 41-7. [DOI:10.1016/j.jsat.2016.08.008] [PMID] [PMCID]

Melemis, S. M. (2015). Relapse prevention and the five rules of recovery. The Yale Journal of Biology and Medicine, 88(3), 325-32. [PMID] [PMCID]

Pilowsky, D. J., Keyes, K. M., Geier, T. J., Grant, B. F., \& Hasin, D. S. (2013). Stressful life events and relapse among formerly alcohol dependent adults. Social Work in Mental Health, 11(2) [DOI:10.1080/15332985.2012.711278] [PMID] [PMCID]

Saakvitne, K. W. (2002). Shared trauma: The therapist's increased vulnerability. Psychoanalytic Dialogues, 12(3), 443-9. [DOI:10.1080/10481881209348678]

Tan, B. Y. Q., Chew, N. W. S., Lee, G. K. H., Jing, M., Goh, Y., Yeo, L. L. L., et al. (2020). Psychological impact of the COVID-19 pandemic on health care workers in Singapore. Annals of Internal Medicine. [DOI:10.7326/M20-1083] [PMID] [PMCID]

The Centre for Addiction and Mental Health (CAMH). (2020). Mental health and COVID-19: Resources for health care workers. Retrieved from https://www.camh.ca/en/health-info/ mental-health-and-covid-19/information-for-professionals

Tong, A., Sainsbury, P., \& Craig, J. (2007). Consolidated criteria for reporting qualitative research (COREQ): A 32-item checklist for interviews and focus groups. International Journal for Quality in Health Care, 19(6), 349-57. [DOI:10.1093/intqhe/ mzm042] [PMID]

Tosone, C., McTighe, J. P., \& Bauwens, J. (2015). Shared traumatic stress among social workers in the aftermath of Hurricane Katrina. The British Journal of Social Work, 45(4), 1313-29. [DOI:10.1093/bjsw/bct194]

Tosone, C., Nuttman-Shwartz, O., \& Stephens, T. (2012). Shared trauma: When the professional is personal. Clinical Social Work Journal, 40, 231-9. [DOI:10.1007/s10615-012-0395-0]
Volkow, N. D. (2020). Collision of the COVID-19 and addiction epidemics. Annals of Internal Medicine. [DOI:10.7326/M201212] [PMID] [PMCID]

Wang, C., Pan, R., Wan, X., Tan, Y., Xu, L., Ho, C. S., et al. (2020). Immediate psychological responses and associated factors during the initial stage of the 2019 Coronavirus Disease (COVID-19) epidemic among the general population in China. International Journal of Environmental Research and Public Health, 17(5), pii: E1729. [DOI:10.3390/ijerph17051729] [PMID] [PMCID]

World Confederation of Cognitive and Behaviouraltherapies (2020). Cognitive Behaviour Therapy (CBT) strategies to improve mental health during the COVID-19 pandemic. Retrieved from https://www.wccbt.org/Downloads/ WCCBT_e-News_March-2020.pdf

World Health Organization. (2020). Country \& technical guidance - Coronavirus disease (COVID-19). Retrieved from https://www.who.int/emergencies/diseases/novel-coronavirus-2019/technical-guidance

Yang, L. H., Wong, L. Y., Grivel, M. M., \& Hasin, D. S. (2017). Stigma and substance use disorders: An international phenomenon. Current Opinion in Psychiatry, 30(5), 378-88. [DOI:10.1097/YCO.0000000000000351] [PMID] [PMCID] 